American Journal of Applied Sciences 9 (7): 988-992, 2012

ISSN 1546-9239

(C) 2012 Science Publications

\title{
A Price Hedging Model in Dynamic Market
}

\author{
${ }^{1}$ Kuo-Wei Lin, ${ }^{1}$ Kuang-Jung Tseng and ${ }^{2}$ Szu-Cheng Cheng \\ ${ }^{1}$ Department of International Business, Hsuan Chuang University, \\ No.48, Hsuan Chuang Road, Hsinchu City 30092, Taiwan, Republic of China \\ ${ }^{2}$ Department of Physics, \\ Chinese Culture University, Taipei 11114, Taiwan, Republic of China
}

\begin{abstract}
Problem statement: Pricing is a problem when a firm has to set a price for the first time. This happens when the firm develops or acquires a new product, introduces its regular product into a new distribution or geographical area, or enters bids on the new contract work. Many companies try to set the price to maximize current profits. They estimate the demand and costs associated with alternative prices and choose the price that maximizes current profit, cash flow, or rate of return on investment. There are, however, some problems associated with the current profit maximizing approach as it assumes that the firm knows its demand and cost functions; in reality, demand is difficult to estimate and is unpredictable. Approach: Due to demand's unpredictability, we assume that it follows a lognormal random walk. Based on this, we develop a mathematical pricing processes model by stochastic calculus, which is similar to the financial process mathematical model. From Ito's lemma, a product's profit correlates with demand, is also unpredictable and follows a random walk. Such random behavior is the marketing risk. Results: By choosing a price strategy to eliminate randomness, called price hedging, we obtain risk-free profit determined by the Black-Scholes equation. This riskless profit, which is predictable, is the same we would get by putting the equivalent amount of cash in a risk-free interest-bearing account. Conclusion: From price hedging and the Black-Scholes equation, we determine the basic product price, which changes with time and demand.
\end{abstract}

Key words: Risk, randomness, price hedging

\section{INTRODUCTION}

Pricing is an important tool for delivering human services and the price of a service is an integral part of that service. Price can be viewed as a statement of value, a reflection of costs, or a marketing strategy. Traditional approaches to pricing have been either cost or market oriented. The former is supply focused, as price reflects the cost of the input used to create the goods or services, whereas the latter is demand focused, as price is a tool for eliciting a certain response from a potential consumer.

Economic theory relates price to cost, competition and elasticity of demand. In competitive markets, the combined forces of competition and the desire of sellers to maximize profits leads sellers to produce to the point at which price, marginal cost and average cost are equal (McCain, 1981). From a marketing perspective, price is a tool for pursuing the goals of an organization (Gabor, 1988). As traditional business practices focus on maximizing profits, price is therefore a strategic tool to elicit consumer demand and enhance product or service image.

In the market, price of the product can create revenue. The other items, goods and product promotion, generate cost. Low prices may generate demand; however, higher prices make outstanding performance possible. In addition, higher prices may lead consumers to view products or services as higher quality.

The stage in service or product life cycle may be an important pricing feature. New services or products that are functionally unique face little competition. Sellers may offer such products at a much higher price than the production cost to allow the company to maximize profit. Another approach is to offer a new service or product at or near the production cost, which allows the seller to penetrate the market and discourages competitors from entering the market. These approaches still maximize sellers' profits, which contain some problems.

To optimize behavior, the agents must know each other's demand and supply schedules and then agree to

Corressponding Author: Kuo-Wei Lin, Department of International Business, Hsuan Chuang University, No.48, Hsuan Chuang Road, Hsinchu City 30092, Taiwan, Republic of China 
adjust their prices to produce clearing. Savings, cash and financial markets are irrelevant in that case because agents do not need to set aside cash for an uncertain future (McCauley, 2007). In reality, it is hard to predict and estimate the demand. Real markets have qualitatively different kinds of agents with real desires and severely limited information and abilities to sort and correctly interpret information. Markets are full of surprise and unpredictability.

This unpredictability is the basic property of markets but creates risk. There are different kind of risks in businesses. It is difficult to choose a strategy to manage risks by just specifying profit and cost. There exist different ways of analyzing risk (Boehlje and Lins, 1998). From the theoretical analysis of risk, the strategies of managing risk were developed (Bodnar et al., 1998). Agricultural companies have already done the management of price risk (Tomek and Peterson, 2001). However, we have little knowledge about how the theories and pratical management of risk are related, especially in the pratical management of sales' risk.

In financial market, it is crucial to realize the behavior of cash and price in the management of price risk. Although the time series of commodity prices are recorded, it is still difficult to manage the risk of these prices. There are considerable uncertainty in the price series, especially some occasional jumps of prices above long-time averages. Thus, the probability distributions of commodity prices are skewed to the right and show kurtosis (Deaton and Laroque, 1992). Price changes nonlinearly and shows correlation between higher moments (Yang and Brorsen, 1992). Due to the complicated time-series characteristics of commodity prices, it is difficult to model these prices and economists did not find the best model.

Basically, the time behavior of commodity price contains fluctuations and randomness and price variability is determined by the information flows of supply and demand. Price trends are related to economic deflation and inflation, changes in population, evolution of technology and the preference shift of consumer. The production cost and price levels are proportional to each other.

To effectively manage risk, it is insufficient to know the price level. Firms can bankrupt due to the occurrence of extreme prices. The management techniques of price risk would handle the randomness of cash prizes if we could analyze and predict the timeseries behavior of commodity prices. Despite numerous efforts in analyzing the behavior of commodity prices, however, obtaining good commodity-price forecasts have been proven to be very difficult. Hence, we can treat the price variability as risk.
To avoid risk, financial products, such as futures or options, have been invented to reduce or hedge risk. For effective hedging, it is important to understand the relationship of price and risk. Decision makers must understand the probability distributions of option or future prices. To obtain optimal hedges of options or futures we have to know and evaluate the parameters of underlying price distributions (McNew and Fackler, 1994). To exercise futures or options, risk exists and their offer risk-management techniques.

\section{MATERIALS AND METHODS}

The pricing options on an asset model by Black and Scholes (1973) assumed that the geometric Brownian motion is the underlying changes of the asset price:

$\mathrm{dS} / \mathrm{S}=\mu \mathrm{dt}+\sigma \mathrm{dW}$

where:

$\mathrm{S}=$ The asset price

$\mu=$ The expected growth rate in $\mathrm{S}$

$\sigma=$ Its volatility and

$\mathrm{dW}=\mathrm{A}$ Wiener process

The option premiums are determined by volatility. Volatility is estimated and predicted by equating the theoretical premium with the market premium by giving the market and strike prices, interest rate of the underlying asset (Black and Scholes, 1973).

Option and future markets are assumed to be efficient. In the assumption of efficient markets the discrepancies of the market premium are supposed to be arbitraged away quickly. It is very difficult to beat the market. There are no systematically repeated patterns in the market, which is a risk. Although the risk is unknown and unpredictable, we can hedge the risk with options. By including European call and stock options to form a protfolio, Black and Scholes (1973) show that a riskless hedge can be created. It is the price that change the value of the portfolio, since the quantities of the assets at a fixed time are unchanged. The return to the hedge portfolio becomes riskless, if quantities of the options and stock in this portfolio are changing constantly in the appropriate manner. Therefore, the riskless rate is earned in the hedge portfolio.

Let $\Delta$ (delta) and $\Pi(\mathrm{S}, \mathrm{t})$ denote the quantities of long-option position and the value of a portfolio with a short-option position, respectively Eq. 1:

$\Pi(S, t)=V(S, t)-\Delta S$ 
where, $\mathrm{S}$ and $\mathrm{V}(\mathrm{S}, \mathrm{t})$ are the the asset price and option value, respectively. If we assume that the motion of the asset price, $\mathrm{S}$, can be described by the following Geometric Brownian motion Eq. 2 (Samuelson, 1965):

$\mathrm{dS} / \mathrm{S}=\mu \mathrm{dt}+\sigma \mathrm{dW}$

Then we can employ Ito's lemma (Malliaris, 1983) to express $\mathrm{dV}(\mathrm{S}, \mathrm{t})$ as the following Eq. 3 :

$$
\mathrm{dV}(\mathrm{S}, \mathrm{t})=\frac{\partial \mathrm{V}}{\partial \mathrm{t}} \mathrm{dt}+\frac{\partial \mathrm{V}}{\partial \mathrm{S}} \mathrm{dS}+\frac{1}{2} \sigma^{2} \mathrm{~S}^{2} \frac{\partial^{2} \mathrm{~V}}{\partial^{2} \mathrm{~S}} \mathrm{dt}
$$

Substituting Eq. 3 for $\mathrm{dV}(\mathrm{S}, \mathrm{t})$ in Eq. 1 yields the following:

$$
\begin{aligned}
& d \Pi(S, t)=d V(S, t)-\Delta d S=\frac{\partial V}{\partial t} d t \\
& +\frac{\partial V}{\partial S} d S+\frac{1}{2} \sigma^{2} S^{2} \frac{\partial^{2} V}{\partial^{2} S} d t-\Delta d S
\end{aligned}
$$

$\mathrm{dS}$ is the only stochastic term in Eq. 4. The dS random terms of Eq. 2 are the risk in our portfolio. By choosing $\Delta(\mathrm{S}, \mathrm{t})=\partial \mathrm{V} / \partial \mathrm{S}$, then, in theory, risk can be reduced or even eliminated and then the randomness reduces to zero. Any reduction in randomness is generally termed hedging. Perfectly eliminating risk by exploiting correlation between two instruments is generally called delta hedging (Wilmott, 2007).

After choosing $\Delta(\mathrm{S}, \mathrm{t})=\partial \mathrm{V} / \partial \mathrm{S}$, we hold a portfolio whose value changes by the following amount and Eq. 4 becoms:

$$
\mathrm{d} \Pi(\mathrm{S}, \mathrm{t})=\frac{\partial \mathrm{V}}{\partial \mathrm{t}} \mathrm{dt}+\frac{1}{2} \sigma^{2} \mathrm{~S}^{2} \frac{\partial^{2} \mathrm{~V}}{\partial^{2} \mathrm{~S}} \mathrm{dt}
$$

This change is completely riskless. If we have a completely risk-free changed $\Pi(S, t)$ in the portfolio value $\Pi(S, t)$ then the change in portfolio value must be the same as if the equivalent amount of money saves in an interest-bearing account, as follows:

$$
\begin{aligned}
\mathrm{d} \Pi(\mathrm{S}, \mathrm{t}) & =\mathrm{r} \Pi(\mathrm{S}, \mathrm{t}) \mathrm{dt}=\mathrm{r}(\mathrm{V}(\mathrm{S}, \mathrm{t})-\Delta \mathrm{S}) \mathrm{dt} \\
& =\mathrm{r}(\mathrm{V}(\mathrm{S}, \mathrm{t})-\mathrm{S} \partial \mathrm{V} / \partial \mathrm{S}) \mathrm{dt}
\end{aligned}
$$

where, $r$ is the interest rate. This is an example of the no arbitrage principle. Substituting Eq. 5 into Eq. 6 we find the following:

$$
\mathrm{r}(\mathrm{V}(\mathrm{S}, \mathrm{t})-\mathrm{S} \partial \mathrm{V} / \partial \mathrm{S}) \mathrm{dt}=\frac{\partial \mathrm{V}}{\partial \mathrm{t}} \mathrm{dt}+\frac{1}{2} \frac{\partial^{2} \mathrm{~V}}{\partial^{2} \mathrm{~S}} \sigma^{2} \mathrm{~S}^{2} \mathrm{dt}
$$

Dividing by dt and rearranging Eq. 7, we obtain a Black-Scholes equation for the option value (Black and Scholes, 1973):

$$
\frac{\partial \mathrm{V}}{\partial \mathrm{t}}+\frac{1}{2} \sigma^{2} \mathrm{~S}^{2} \frac{\partial^{2} \mathrm{~V}}{\partial^{2} \mathrm{~S}}+\mathrm{rS} \frac{\partial \mathrm{V}}{\partial \mathrm{S}}-\mathrm{rV}=0
$$

The differential Eq. 8 can be solved with the appropriate boundary condition and at a terminal date. To find the solution it is transformed into the diffusion equation from physics.

\section{RESULTS AND DISCUSSION}

The freedom of choosing a portfolio to eliminate risk is important to managing risk. From a risk-free portfolio, we can estimate the amount of risk from choosing a different portfolio. This gives a company marketing freedom as it can adjust the price of its product or service. This price-adjustment freedom can eliminate the randomness of a product's profits. Without randomness and risk, a product's profits become deterministic. The riskless profits must be the same as if the equivalent amount of money saves in an interest-bearing account. We show that the very basic price of a product or service is determined by the riskfree profits.

How are prices set? Through most of history, prices were negotiated by sellers and buyers. Sellers would ask for a price higher than they expected to receive and buyer would offer less than they expected to pay. Through bargaining, they would arrive at an acceptable price. All the elements in marketing products produce costs except price which generates revenues. The marketing executives treat pricing and price competition as the important issue in marketing. Many companies are lack of good strategies to handle pricing. They choose the pricing strategies of too cost consideration, not flexible enough to meet market changes and independent of the rest market. Many companies can obtain their maxima current profits by choosing the market-oriented strategy which estimates the demand and costs and sets the price to maximize cash flow and return rate on investment. A firm has to know its cost and demand functions in order to maximize current profits. In fact, it is difficult to estimate and predict the demand. Also, there are many unknown marketing-mixing variables and reactions from competitors. Due to its unpredictability, the demand of a product or service is randomized. No known pattern of consumers is predictable.

From its randomness, the motion of the demand quantity, Q, is described by Geometric Brownian motion: 
Am. J. Applied Sci., 9 (7): 988-992, 2012

$\mathrm{dQ} / \mathrm{Q}=\mu \mathrm{dt}+\sigma \mathrm{dW}$

where $\mu, \sigma$ and $\mathrm{dW}$ are the expected growth rate, volatility and Wiener process in $\mathrm{Q}$, respectively. Assume that the profit $\mathrm{F}(\mathrm{Q}, \mathrm{t})$ and $\cos \mathrm{C}(\mathrm{Q}, \mathrm{t})$ of a product are the functions of the demand quantity $\mathrm{Q}$ and time $t$. Then the profit is given by the total revenue minus cost:

$\mathrm{F}(\mathrm{Q}, \mathrm{t})=\mathrm{PQ}-\mathrm{C}(\mathrm{Q}, \mathrm{t})$

where, $\mathrm{P}$ is the price of a product.

We can rearrange Eq. 10 and write it in the following differential form:

$\mathrm{dC}(\mathrm{Q}, \mathrm{t})=\mathrm{PdQ}-\mathrm{dF}(\mathrm{Q}, \mathrm{t})$

We then apply Ito's lemma (Malliaris, 1983) to express $\mathrm{dF}(\mathrm{Q}, \mathrm{t})$ as the following:

$$
\mathrm{dF}(\mathrm{Q}, \mathrm{t})=\frac{\partial \mathrm{F}}{\partial \mathrm{t}} \mathrm{dt}+\frac{\partial \mathrm{F}}{\partial \mathrm{S}} \mathrm{dQ}+\frac{1}{2} \sigma^{2} \mathrm{Q}^{2} \frac{\partial^{2} \mathrm{~F}}{\partial^{2} \mathrm{Q}} \mathrm{dt}
$$

Substituting Eq. 12 for $\mathrm{dF}(\mathrm{Q}, \mathrm{t})$ in Eq. 11 yields the following:

$$
\mathrm{dC}(\mathrm{Q}, \mathrm{t})=\mathrm{PdQ}-\left(\frac{\partial \mathrm{F}}{\partial \mathrm{t}} \mathrm{dt}+\frac{\partial \mathrm{F}}{\partial \mathrm{S}} \mathrm{dQ}+\frac{1}{2} \sigma^{2} \mathrm{Q}^{2} \frac{\partial^{2} \mathrm{~F}}{\partial^{2} \mathrm{Q}} \mathrm{dt}\right)
$$

The only stochastic term in Eq. 13 is dQ. The rest are deterministic. The dQ random terms which follow a lognormal random walk from Eq. 9 are the risk in our revenue. From the freedom a company has to adjust price, this risk can be eliminated by choosing $\mathrm{P}(\mathrm{Q}, \mathrm{t})=$ $\partial \mathrm{F} / \partial \mathrm{Q}$ and then, the randomness is reduced to zero. This reduction in randomness is termed pricehedging and is completely riskless. If we have a completely riskfree change $\mathrm{dC}(\mathrm{Q}, \mathrm{t})$ in the cost $\mathrm{C}(\mathrm{Q}, \mathrm{t})$, then it must be the same return obtained from depositing the equal amount of investment cash in an interest-bearing account, as follows:

$$
\begin{aligned}
\mathrm{dC}(\mathrm{Q}, \mathrm{t}) & =\mathrm{r} \mathrm{C}(\mathrm{Q}, \mathrm{t}) \mathrm{dt}=\mathrm{r}(\mathrm{PQ}-\mathrm{F}(\mathrm{Q}, \mathrm{t})) \mathrm{dt} \\
& =\mathrm{r}(\mathrm{Q} \partial \mathrm{F} / \partial \mathrm{S}-\mathrm{F}(\mathrm{Q}, \mathrm{t})) \mathrm{dt}
\end{aligned}
$$

where, $r$ is the interest rate. This is an example of the no arbitrage principle.

Substituting Eq. 13 into Eq. 14 we find the following:

$$
r(Q \partial F / \partial S-F(Q, t)) d t=-\frac{\partial F}{\partial t} d t-\frac{1}{2} \sigma^{2} Q^{2} \frac{\partial^{2} F}{\partial^{2} Q} d t
$$

Dividing by dt and rearranging Eq. 15 we get the following:

$$
\frac{\partial \mathrm{F}}{\partial \mathrm{t}}+\frac{1}{2} \sigma^{2} \mathrm{Q}^{2} \frac{\partial^{2} \mathrm{~F}}{\partial^{2} \mathrm{Q}}+\mathrm{rQ} \frac{\partial \mathrm{F}}{\partial \mathrm{Q}}-\mathrm{rV}=0
$$

The Black-Scholes equation was derived for the riskless profit of a product. We can solve the Eq. 16 by transforming it into the evolution equation of heat in physics.

To obtain $\mathrm{F}(\mathrm{Q}, \mathrm{t})$, the differential equation (16) with the boundary conditions and the initial condition has to be solved. From price hedging, $P(Q, t)=d F / d Q$, then the price of a product is determined. Price hedging is an example of a dynamic hedging strategy. From one time step to the next the quantity $\mathrm{P}(\mathrm{Q}, \mathrm{t})=\mathrm{dF} / \mathrm{dQ}$ changes since it is, like $F(Q, t)$, a function of the ever-changing variables $\mathrm{Q}$ and $\mathrm{t}$. Because it is riskless, the price determined by price hedging is the very basic price of a product. From price hedging, how much risk of choosing a different price strategy can be determined. Risk management becomes possible in marketing.

\section{CONCLUSION}

This study investigated the pricing problem that a firm has to decide the original price of a product. This happens when a firm introduces a new product, distributes its product into a new geographical area and sets bids on new contract. Many companies obtain their maxima current profits by setting the price to maximize cash flow and return rate on investment. A firm has to know its cost and demand functions in order to maximize current profits. In fact, it is difficult to estimate and predict the demand. Also, there are many unknown marketing-mixing variables and reactions from competitors. Due to its unpredictability, the demand of a product or service is randomized. No known pattern of consumers is predictable.

The finding shows that a firm has to know its cost and demand functions in order to maximize current profits. In reality, there are many unknown marketingmixing variables and reactions from competitors. The firm has a problem to estimate and predict the demand. The demand is randomized and its function is supposed to follow a lognormal random walk. The mathematics of randomness is the stochastic calculus. Then, the profit, as a function of marketing risk is due to the randomness of the demand. From the freedom of the price adjustment of a company, this risk can be eliminated by choosing a price strategy and the 
randomness is reduced to zero. This reduction in randomness is termed price hedging and completely riskless. The riskless profit is predictable and determined by the Black-Scholes equation. This profit becomes the same return obtained from depositing the equal amount of investment cash in an interest-bearing account that is riskless.

From pricing hedging and the Black-Scholes equation, the basic strategy of setting the price of a product is given. The price follows the time series of demand. With respect to market changes such a dynamical price can adjust often enough and create the riskless profit. The price hedging theory develops a new strategy in the risk management of marketing.

\section{REFERENCES}

Black, F. and M. Scholes, 1973. The pricing of options and corporate liabilities. J. Polit. Econ., 81: 637654.

Bodnar, G.M., R.C. Marston and G. Hayt, 1998. Wharton survey of financial risk management by U.S. non-financial firms. Finan. Manag., 27: 70-91.

Boehlje, M.D. and D.A. Lins, 1998. Risks and risk management in an industrialized agriculture. Agric. Finan. Rev., 58: 1-16.

Deaton, A. and G. Laroque, 1992. On the behaviour of commodity prices. Rev. Econ. Stud., 59: 1-23. DOI: $10.2307 / 2297923$
Gabor, A., 1988. Pricing: Concepts and Methods for Effective Marketing. 2nd Edn., Aldershot Gower, ISBN-10: 0566027038 pp: 378.

Malliaris, A.G., 1983. Ito's calculus in financial decision making. SIAM Rev., 25: 481-496.

McCain, R.A., 1981. Markets, Decisions and Organizations: Intermediate Microeconomic Theory. 1st Edn., Prentice Hall, New Jersey, ISBN10: 0135578841 pp: 555.

McCauley, J.L., 2007. Econophysics and Finance from A Physicist's Standpoint. 1st Edn., Cambridge University Press, New York, ISBN-10: 0521824478 pp: 209.

McNew, K.P. and P.L. Fackler, 1994. Nonconstant optimal hedge ratio estimation and nested hypotheses tests. J. Futures Markets, 14: 619-635. DOI: 10.1002/fut.3990140508

Samuelson, P.A., 1965. Rational theory of warrant pricing. Indus. Manage. Rev., 6: 13-31.

Tomek, W.G. and H.H. Peterson, 2001. Risk management in agricultural markets: A review. J. Futures Markets, 21: 953-985. DOI: 10.1002/fut.2004

Wilmott, P., 2007. Quantitative Finance. 2nd Edn., Wiley and Sons, New York, ISBN-10: 9780470319581 pp: 695.

Yang, S.R. and B.W. Brorsen, 1992. Nonlinear dynamics of daily cash prices. Am. J. Agric. Econ., 74: 706-715. DOI: $10.2307 / 1242584$ 